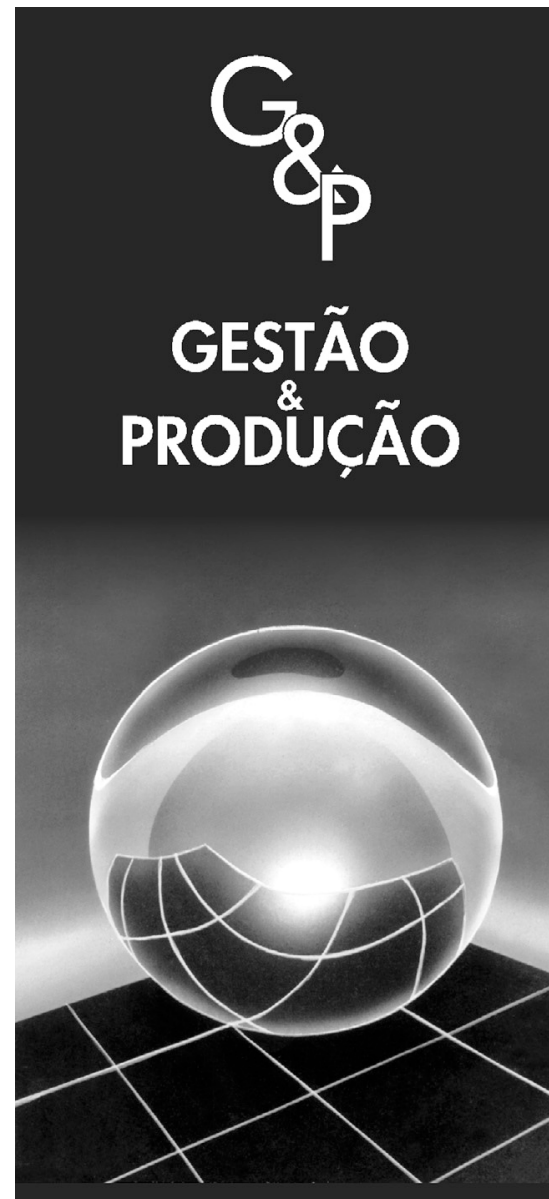

\title{
ANÁLISE DA GESTÃO DA CADEIA DE SUPRIMENTOS NA INDÚSTRIA DE COMPUTADORES
}

\author{
Paulo H. Parra \\ Sílvio R. I. Pires \\ Programa de Pós-graduação em \\ Engenharia de Produção - UNIMEP, \\ Via Santa Bárbara-Iracemápolis, km 1, \\ Santa Bárbara do Oeste, SP, CEP 13450-000, \\ e-mail: sripires@unimep.br
}

v.10, n.1, p.1-15, abr. 2003

\section{Resumo}

Nos últimos anos a competição tem crescido significativamente no mundo industrial, provocando o surgimento de novos desafios e oportunidades na forma de organizar e gerenciar a produção. Nesse contexto, a gestão da cadeia de suprimentos (Supply Chain Management - SCM) tem emergido como uma nova e promissora maneira de obter vantagens competitivas no mercado. Por sua vez, a indústria de computadores apresenta um conjunto de fatores que dificultam uma gestão mais efetiva da cadeia de suprimentos, em razão, principalmente, da velocidade das inovações tecnológicas no setor. Este trabalho tem por objetivo básico apresentar uma análise geral da gestão da cadeia de suprimentos na indústria de computadores, com foco na cadeia de abastecimento. O estudo teve o suporte de uma pesquisa conduzida em um grande e representativo produtor mundial de computadores que opera no Brasil.

Palavras-chave: gestão da cadeia de suprimentos, indústria de computadores, gestão da cadeia de abastecimento. 


\section{Introdução}

A competição entre empresas industriais cresceu significativamente desde o início dos anos 90. Atualmente, muitas empresas, mesmo localizadas em países em processo de industrialização, têm enfrentado mercados altamente competitivos, com novos e crescentes critérios para competir e garantir a própria sobrevivência. Marcas e companhias globais tendem a dominar a maioria dos mercados, com tendência para o marketing mundial de produtos. Não somente a marca tem se tornado comum aos diferentes mercados individuais, como também muitos produtos têm caminhado para uma padronização global e para customizações locais. Christopher (1997) também relata que, ao mesmo tempo, a empresa de classe mundial tem revisado seu foco de atuação, possibilitando o surgimento de fontes de fornecimento para produção em dimensão global.

Nesse contexto, o nível de competitividade industrial tem imposto ao mercado novos padrões de custo, qualidade, desempenho de entregas e flexibilidade, o que gera uma série de novos desafios e fontes de vantagem competitiva nas empresas.

Dentre as novas maneiras de obter vantagens surgidas nos últimos anos, tem se destacado muito a gestão da cadeia de suprimentos (supply chain management - SCM), a qual tem emergido como novo modelo gerencial e competitivo para as empresas industriais. Adicionalmente, as compras externas de bens e serviços respondem por grande parte dos recursos financeiros das empresas, favorecendo a visão de que a cadeia de abastecimento é um campo vital a ser explorado (Slack et al., 1996).

Por sua vez, nos últimos anos, a indústria de informática, mais especificamente a indústria de computadores, tornou-se uma das mais representativas e influentes do mundo. Entretanto, apresenta uma série de particularidades que tendem a dificultar uma gestão eficaz de sua cadeia de suprimentos. Tais características não são exclusivas dessa indústria, mas potencializam-se nela, principalmente pela competição acirrada em nível mundial que é marcada pela velocidade nas inovações tecnológicas introduzidas, bem como pelos curtos ciclos de vida de produtos e modelos.

Assim, este trabalho tem por objetivo básico apresentar uma análise geral da gestão da cadeia de suprimentos da indústria de computadores, com foco na cadeia de abastecimento (inbound). A análise apresentada teve o suporte de um estudo de caso conduzido em um grande e representativo produtor mundial de computadores que opera no Brasil.

A seguir, o artigo apresenta uma sucinta revisão do tema gestão de cadeias de suprimentos, o qual serve de base conceitual para as análises a serem apresentadas posteriormente.

\section{Gestão da cadeia de suprimentos}

Conforme relatado, nos últimos anos a gestão da cadeia de suprimentos tem emergido como modelo competitivo estratégico e gerencial para empresas industriais. Segundo Poirier \& Reiter (1997), uma cadeia de suprimentos (supply chain) é um sistema por meio do qual empresas e organizações entregam produtos e serviços a seus consumidores, em uma rede de organizações interligadas.

Recentemente, alguns autores têm atribuído à SCM o status de filosofia de negócios, e diversas definições e visões têm sido encontradas na literatura (Svensson, 2002).

Neste trabalho será considerado que a SCM trata basicamente da integração holística dos processos de negócios (business process) por intermédio da cadeia produtiva, com objetivo de atender o consumidor final mais efetivamente, isto é, sendo eficiente e eficaz simultaneamente (Pires et al., 2001). A SCM também pode ser considerada uma visão expandida, atualizada e, sobretudo, holística da administração tradicional de materiais, abrangendo a gestão de toda a cadeia produtiva de forma estratégica e integrada. 
A SCM pressupõe, fundamentalmente, que as empresas devem definir suas estratégias competitivas e funcionais por meio de posicionamentos (como fornecedores e como clientes) nas cadeias produtivas em que se inserem (Pires, 1998). De maneira geral, a SCM busca intensificar, somar e amplificar os benefícios de uma gestão integrada da cadeia de suprimentos. Assim, as estratégias e as decisões deixam de ser formuladas e firmadas sob a perspectiva de uma única empresa e passam a fazer parte da cadeia produtiva como um todo.

A SCM também introduz uma importante mudança no modelo competitivo ainda vigente em muitas empresas, ao considerar que cada vez mais a competição no mercado tende a ocorrer no nível das cadeias produtivas e não apenas no nível das unidades de negócios (isoladas), como estabelecia o tradicional trabalho de Porter (1980).

Isso resulta em um modelo competitivo com base no fundamento de que cada vez mais a competição se dará entre unidades de negócios virtuais, ou seja, entre cadeias produtivas. Assim, atualmente, as mais efetivas práticas na SCM visam obter unidade de negócio virtual, a qual consegue manter a maioria dos benefícios da tradicional integração vertical, eliminando as desvantagens em termos de custo e perda de flexibilidade inerentes a ela (Vollmann \& Cordon, 1996). Uma unidade de negócios virtual é formada pelo conjunto de unidades (geralmente representadas por empresas distintas) que compõem determinada cadeia produtiva, conforme ilustra a Figura 1.

Em geral, pode-se afirmar que o modelo competitivo e gerencial da SCM enfatiza que cada cadeia produtiva agirá como organização virtual de negócios, devendo se preocupar com a competitividade de produtos e serviços perante o consumidor final e com o desempenho da cadeia produtiva como um todo.

\subsection{Reestruturação e consolidação da cadeia de suprimentos}

Nos últimos anos, um dos pilares da SCM no mundo industrial tem sido o processo de reestruturação e consolidação das bases de fornecedores e clientes. Basicamente, esse processo seleciona (geralmente reduz) e aprofunda as relações com um conjunto seleto de fornecedores e clientes com os quais se deseja estabelecer parceria.

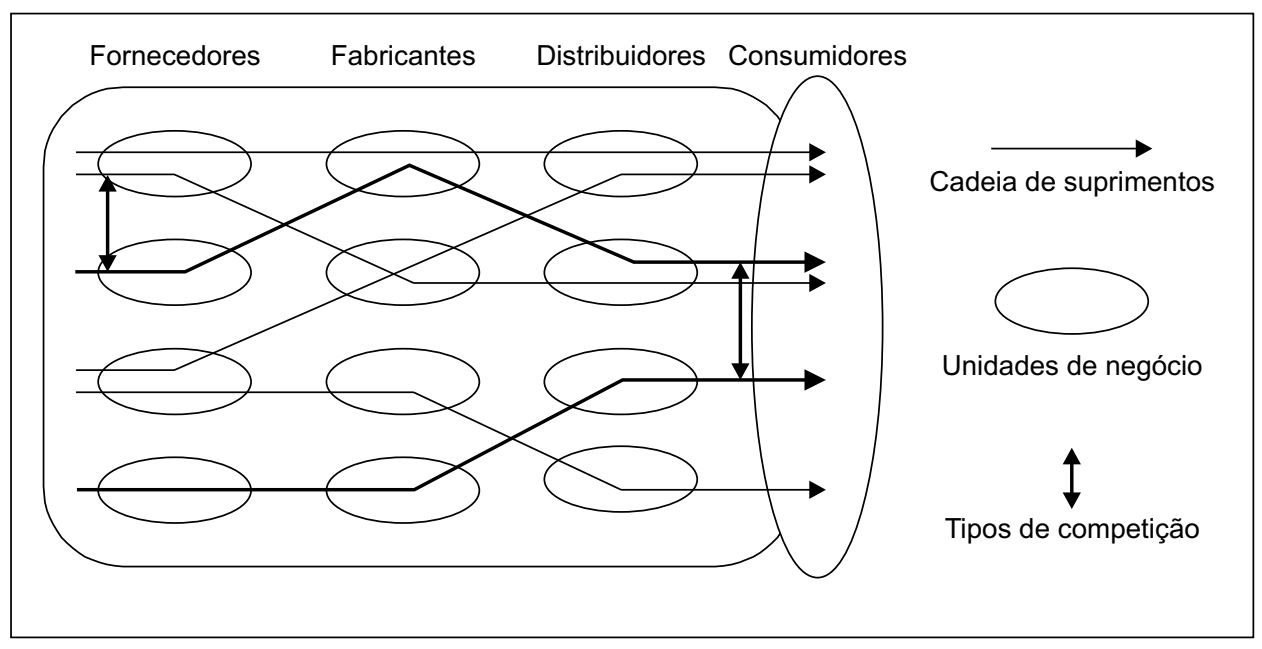

Figura 1 - Competição entre unidades de negócios virtuais (Pires, 1998). 
Assim, nesse processo serão decididos quais relacionamentos entre consumidores, fornecedores e provedores de serviço são mais ou menos importantes na otimização da SCM (Collins et al., 1997). Segundo Pires (1998), esse processo pode ser dividido em duas etapas básicas de transformação e melhoria da SCM: a reestruturação e a consolidação.

Por reestruturação entende-se a simplificação da cadeia de suprimentos, com o objetivo de melhorar principalmente sua eficiência. A questão básica dessa etapa é com quem a empresa pretende construir parcerias e simplificar os processos de comunicação. Na maioria das vezes, a reestruturação acaba incorrendo na redução do número de fornecedores e, eventualmente, do número de clientes. Um exemplo dessa situação, menos comum, é a solicitação de algumas empresas para que pequenos clientes comprem por meio de distribuidores e não diretamente, reduzindo o número de clientes diretos e os custos decorrentes de tal prática.

Já a consolidação consiste no aprofundamento e no estreitamento das relações de parceria e canais de comunicação com a base de fornecedores e clientes após a reestruturação. Contudo, o sucesso dessa etapa requer postura de confiança, cooperação e relação ganha-ganha entre os componentes da cadeia produtiva.

No que tange à formação de parcerias entre as organizações, Cooper \& Gardner (1993) indicam cinco pontos importantes no estabelecimento e na consolidação do relacionamento, os quais vão além da reciprocidade. São eles:

- Assimetria: reflete a habilidade de uma organização em exercer poder, influência ou controle sobre outra.

- Reciprocidade: é baseada na mutualidade benéfica em atingir objetivos comuns. Contrária à assimetria, a reciprocidade estabelece relação positiva entre as partes, pois implica cooperação, colaboração e coordenação entre as partes.
- Eficiência: aparece quando há necessidade interna de a empresa melhorar a relação custo/benefício de algum processo. Sendo assim, ela transferirá para uma outra organização um processo ineficiente.

- Estabilidade: reflete a tentativa de adaptar ou reduzir as incertezas de algum negócio, ou seja, as empresas que utilizam essa razão buscam parcerias que lhes garantam um futuro mais confiável.

- Legitimidade: a legitimidade reflete como os resultados e as atividades de uma empresa são justificados. Por exemplo, um negócio com uma grande montadora de automóveis pode ajudar a estabelecer a legitimidade de um pequeno fabricante de autopeças.

\subsection{Globalização da cadeia de suprimentos}

Conforme relatado na introdução deste trabalho, as marcas e as companhias globais dominam muitos mercados. Ao longo das últimas décadas houve forte tendência para o marketing mundial de produtos sob a administração de grandes marcas, como Coca-Cola, IBM, Toyota, Microsoft, dentre outras. Além de as marcas serem comuns nos mercados de cada país individualmente, os produtos também sofreram uma padronização geral. Ao mesmo tempo, as companhias globais revisaram seu antigo enfoque (mais regional) e atualmente procuram recursos em base global (Christopher, 1997). Essas companhias procuram ampliar seus negócios pela lógica da expansão dos mercados e da redução dos custos por economias de escala na compra de insumos e na produção, sendo cada vez mais comum o uso de operações concentradas de manufatura.

Contudo, apesar dessa lógica, deve-se reconhecer que há certos desafios à empresa global. Primeiro, os mercados mundiais não são homogêneos e ainda requerem customizações locais em muitas categorias de produtos. Segundo, há 
elevado nível de complexidade logística na execução de uma SCM em âmbito global, o que pode resultar em custos altos e prazos excessivamente longos para os lead times de entregas. O custo do transporte, em razão do uso de fontes de fornecimento distantes, pode se sobrepor a possíveis reduções de custo obtidas pela economia de escala.

A tendência para o uso de manufatura e marketing em escala global está evidenciando a SCM e seus processos logísticos como fatores críticos de sucesso. A complexidade da tarefa logística é influenciada por fatores como número crescente de produtos, curtos ciclos de vida do produto e crescimento do mercado e do número de canais de fornecimento.

\subsection{Gestão estratégica de lead times na cadeia de suprimentos}

De acordo com Christopher (1997), os clientes em todos os mercados industriais estão cada vez mais sensíveis ao tempo. Em outras palavras, eles o valorizam e isso se reflete em seus comportamentos de compra. Cada vez mais os compradores procuram fornecedores que ofereçam menores prazos e atendam a seus requisitos de qualidade.

Nos mercados de consumo, os clientes escolhem entre as marcas disponíveis no momento. Portanto, se a marca preferida não estiver no estoque, provavelmente será adquirida uma substituta.

Segundo Christopher \& Braithwaite (1989), há três fatores de pressão nos mercados sensíveis ao tempo:

- redução dos ciclos de vida dos produtos;

- esforço para manter estoques reduzidos;

- mercados voláteis com base em previsões poucos confiáveis.

A redução do ciclo de vida dos produtos faz com que se diminua o tempo disponível para desenvolver e lançar novos produtos. Assim, a habilidade de gerenciar adequadamente o desenvolvimento, a fabricação e os processos logísticos dos produtos torna-se elemento-chave na estratégia competitiva de uma empresa.

O esforço para manter estoques reduzidos é um dos fenômenos mais pronunciados nos últimos anos no mundo industrial. Sejam estoques de matérias-primas, de materiais em processo de produção, de componentes ou de produtos acabados, a pressão tem sido para a liberação do capital neles aplicado, o que, consequientemente, reduz os custos de manutenção.

Um problema constante que aflige a maioria das organizações, especialmente aquelas que produzem para estoque, é a incerteza das previsões. Não importa quão sofisticadas sejam as técnicas de previsão empregadas, a volatilidade dos mercados leva essas previsões a estarem sempre sujeitas a erros. Os erros de previsão tendem a provocar aumento indesejado nos lead times de compras e produção.

\section{Gestão da cadeia de abastecimento na indústria de computadores}

Conforme definido anteriormente, uma cadeia de suprimentos abrange o fluxo de materiais e informações desde a fonte de matéria-prima primária até a entrega do produto acabado ao consumidor final. Assim, toda empresa industrial inserida em uma cadeia de suprimentos apresenta uma cadeia de abastecimento (inbound chain) e uma de distribuição (outbound).

Neste trabalho o interesse reside no estudo da cadeia de abastecimento da indústria de computadores, com o objetivo de:

- apresentar uma análise da gestão da cadeia de suprimentos, verificando a influência de algumas de suas estratégias no desempenho de sua cadeia de abastecimento;

- estruturar os elementos-chave para o aprimoramento da cadeia de abastecimento do setor. 
A pesquisa foi conduzida com base, principalmente, na análise da realidade e em dados de uma empresa representativa e líder na indústria de computadores, a qual atua globalmente e apresenta operações de manufatura no Brasil. A empresa que serviu de base para o estudo não será identificada, sendo o trabalho conduzido de forma exploratória. Em termos de taxonomia de métodos de pesquisa, foi utilizada a chamada pesquisa-ação ou de observação participante (Dane, 1990). Nesse caso, o pesquisador participa diretamente ou está envolvido com os eventos e/ou fenômenos observados. Esse fato fez com que significativo volume de conhecimento tácito (não formalizado) da empresa estudada e do setor industrial pudesse ser relatado no decorrer do trabalho.

O estudo foi subdividido em três etapas distintas, identificando:

- as principais características da indústria de computadores;

- o modelo predominante de gestão da cadeia de suprimentos;

- os elementos-chave de aprimoramento da cadeia de abastecimento.

\subsection{Características da indústria de computadores}

Pode-se afirmar que a indústria de computadores apresenta uma série de características que dificultam a gestão eficaz de sua cadeia de suprimentos. Essas características não são exclusivas desse tipo de indústria, mas potencializamse pela velocidade e pelas constantes inovações. Essas características são:

- curtos ciclos de vida;

- grande número de produtos;

- baixa previsibilidade da demanda;

- grande variabilidade do mercado;
- grande customização de atendimento;

- muitos canais de fornecimento.

Os curtos ciclos de vida dos produtos ocorrem em função das constantes inovações tecnológicas no setor. Dessa maneira, as empresas se vêem obrigadas a lançar novos produtos constantemente, acompanhando o ritmo acelerado da inovação na indústria.

O grande número de produtos associa-se à diversidade de aplicações dos computadores. Essa diversidade abrange desde um computador pessoal até um servidor de grande porte, ou seja, para cada necessidade específica há um produto diferenciado.

A baixa previsibilidade da demanda tem sua origem em diversos fatores, com destaque para a enorme gama de produtos e também para a grande variabilidade do mercado. Assim, podese dizer que a previsibilidade da demanda tende a ser inversamente proporcional ao número de produtos e/ou mercados, os quais são enormes nesse tipo de indústria.

A grande variabilidade do mercado se deve à constante busca por parte da indústria em prover soluções/produtos para todo o tipo de necessidade. Isso faz com que o mercado se torne cada vez mais amplo e diferenciado.

Já a grande customização de atendimento associa-se a dois fatores centrais. O primeiro relaciona-se ao fato de que os consumidores/ mercado estão cada vez mais exigentes, demandando produtos que atendam a suas necessidades específicas. Já o segundo relaciona-se à concorrência acirrada desse tipo de indústria, cuja customização de atendimento apresenta uma estratégia eficiente de aumento de vendas.

O constante aumento dos canais de abastecimento ocorre em função da globalização, que se encontra em estágio bem avançado na indústria de computadores, ou seja, o processo de globalização fomenta a multiplicação dos canais de fornecimento. 
Essas características foram divididas em três grandes grupos, apresentados na Figura 2, que ilustra os principais desafios encontrados pela SCM na indústria de computadores. Pela relevância na SCM e, em especial, na gestão da cadeia de abastecimento, algumas características próprias da indústria de computadores serão destacadas a seguir.

\subsubsection{Unidades de negócios}

Em razão de sua complexidade, a indústria de computadores não costuma ser tratada como elemento único, visto que há mercados e produtos diferenciados que forçam a segmentação do setor. Para ilustrar, pode-se citar o caso de um profissional liberal que deseja melhorar seus serviços adquirindo um computador, o que difere em muito de uma empresa que busca um novo servidor para expandir seus negócios. Tendo em vista essa diferenciação no mercado, a indústria de computadores usualmente divide sua atuação em três unidades de negócio distintas:

- unidade de consumidores;

- unidade corporativa;

- unidade de servidores.

Em seguida, essas unidades de negócio serão analisadas sob a perspectiva de três dimensões que consideramos básicas no setor: o mercado, o produto e a fabricação.

\section{Unidade de consumidores}

A unidade de consumidores envolve todos os produtos e acessórios voltados à utilização pessoal de um computador. A característica desse mercado é a atuação no varejo, ou seja, o cliente final normalmente é uma pessoa física que busca um equipamento para sua casa, escritório ou pequena empresa.

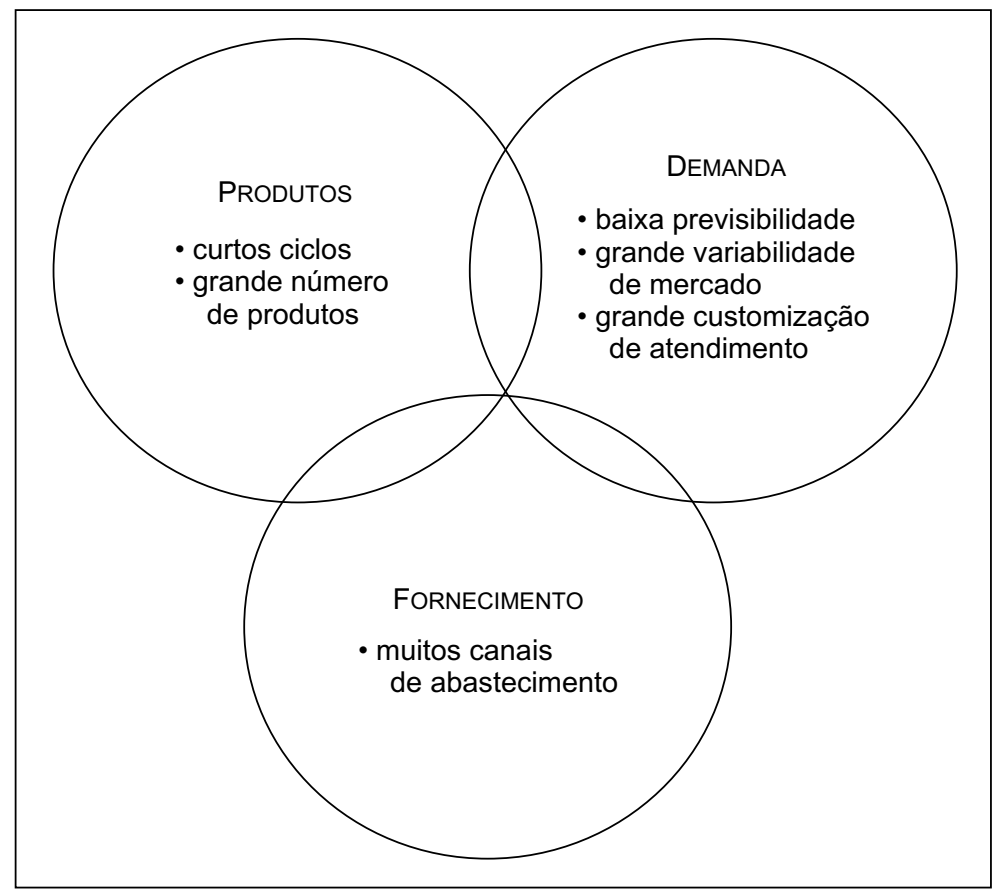

Figura 2 - Principais desafios da SCM na indústria de computadores. 
Já os produtos dessa unidade de negócio apresentam um ciclo de vida extremamente curto (de 3 a 6 meses) em função da constante evolução tecnológica que se aplica a esse tipo de produto (hardware e software). Além disso, os produtos dessa unidade possuem duas segmentações claras. A primeira é caracterizada por computadores de baixo custo, com certa tecnologia agregada, e a segunda, por computadores com tecnologia mais avançada, alto poder de processamento e, conseqüentemente, preço mais elevado.

Quanto à fabricação, tem-se a produção em grande escala, voltada ao abastecimento dos estoques dos centros de distribuição e geralmente associada a uma pequena diversidade de produtos finais.

\section{Unidade corporativa}

A unidade corporativa engloba produtos e acessórios destinados tanto a empresas grandes como pequenas. Quanto ao mercado, tem-se que a última geração em tecnologia não está em primeiro plano, mas a diferenciação, ou seja, preza-se pela configuração, pelo atendimento, pela execução e pela entrega diferenciada.

Os produtos dessa divisão possuem um ciclo de vida médio (de 6 a 12 meses), mas com grande diversidade de tipos (famílias), projetados para cada tipo de aplicação. Outra particularidade está relacionada à customização, muitas vezes requerida pelos clientes, que pode envolver a configuração de algum componente (hardware) ou até mesmo de sistemas operacionais (software).

Em relação à fabricação, tem-se basicamente o atendimento de ordens (pedidos). Esse tipo de atendimento torna a fabricação uma atividade complexa, em razão da grande variedade de produtos e ordens a executar. Em contrapartida, apresenta processos de fabricação otimizados, por se tratarem de produtos com ciclo de vida relativamente médio.

\section{Unidade de servidores}

Essa divisão está voltada para a fabricação de servidores, classificados como computadores de médio porte. Nessa unidade tem-se um mercado voltado para médias e grandes empresas, bem como centros de pesquisa. Especificamente no Brasil, pode-se dizer que esse mercado está em plena expansão, diante do crescimento do segmento de telecomunicações e aplicações da Internet.

Os produtos dessa unidade apresentam ciclo de vida médio (de 6 a 12 meses) e com pequena gama de variação. Outra particularidade desse grupo está na grande variedade de itens opcionais atrelados à compra do produto em si.

Já no que tange à f 'abricação, tem-se nesta divisão a presença de um produto com baixo volume de produção, mas com alto valor agregado. Sendo assim, sua execução se dá estritamente por meio de pedidos de clientes, que termina na maioria das vezes com a entrega direta, sem intermédio de distribuidores.

Essa relação entre as unidades de negócio e a perspectiva das três dimensões (mercado, produto e fabricação) é ilustrada na Tabela 1.

\subsubsection{Configuração do produto}

$\mathrm{Na}$ indústria de computadores, usualmente o computador é tratado como unidade de processamento central (central processing unit $C P U)$. Essa unidade de processamento é formada pela montagem de diversos elementos que juntos formam um produto final. Esses elementos são: microprocessador, teclado, disco rígido, placa processadora, floppy drive, $\mathrm{CD}$ drive, placa gráfica, DVD drive, placa de fax/modem, memória, placa de rede, embalagem, chassis, documentação e software.

Esses elementos podem ser estruturados em dois grupos: a plataforma, que varia conforme o produto, e os configuradores, que definem o produto final efetivamente, conforme ilustra a Tabela 2. 
Tabela 1 - Relação entre as unidades de negócio e as três dimensões analisadas.

\begin{tabular}{clll}
\hline \multirow{2}{*}{$\begin{array}{c}\text { Unidade de } \\
\text { negócio }\end{array}$} & \multicolumn{3}{c}{ Dimensão } \\
\cline { 2 - 4 } Consumidores & \multicolumn{1}{c}{ Mercado } & \multicolumn{1}{c}{ Produto } & \multicolumn{1}{c}{ Fabricação } \\
\hline \multirow{2}{*}{ Corporativos } & Cliente no varejo & $\begin{array}{l}\text { Curto ciclo de vida } \\
\text { Baixa variedade }\end{array}$ & $\begin{array}{l}\text { Altos volumes para } \\
\text { estoque }\end{array}$ \\
\hline \multirow{2}{*}{ Servidores } & $\begin{array}{l}\text { Enfoque na diferenciação } \\
\text { Clientes corporativos }\end{array}$ & $\begin{array}{l}\text { Médio ciclo de vida } \\
\text { Alta variedade }\end{array}$ & $\begin{array}{l}\text { Customização contra } \\
\text { ordens }\end{array}$ \\
& Enfoque na diferenciação & Médio ciclo de vida & $\begin{array}{l}\text { Baixos volumes } \\
\text { Customização contra } \\
\text { ordens }\end{array}$ \\
\hline
\end{tabular}

Tabela 2 - Componentes básicos de um computador.

\begin{tabular}{cll}
\hline Grupo & \multicolumn{1}{c}{ Plataforma } & \multicolumn{1}{c}{ Configuradores } \\
\hline \multirow{5}{*}{ Componentes } & Chassis & Microprocessador \\
& Teclado & Memória \\
& Placa processadora & Disco rígido \\
& Placa gráfica & DVD drive \\
& Embalagem & Floppy drive \\
& Documentação & CD drive \\
& Software & Placa de fax/modem \\
& & Placa de rede \\
\hline
\end{tabular}

A combinação entre plataforma e configuradores gera inúmeras possibilidades para cada produto. Por exemplo, um produto com 5 variações para cada um dos 8 configuradores e 4 plataformas diferentes gerará um total de 160 combinações.

\subsubsection{Posicionamento de materiais}

O mercado de computadores é extremamente sensível em termos de variações de volume, pois lida com produtos de alta tecnologia e com inovações acontecendo a todo o momento. Por sua vez, a inovação requer a maior flexibilidade possível no posicionamento (disponibilizar para uso) de materiais, pois é por intermédio da excelência desse posicionamento que se garante o atendimento do cliente final. No entanto, a flexibilidade precisa estar atrelada a baixos níveis de inventário, bem como a altos giros de estoque, pois disso depende a saúde financeira das empresas.

Atualmente, na indústria de computadores tem-se cada vez mais a aplicação de estratégias de posicionamento de materiais que se dão principalmente pela análise dos seguintes fatores:

- valor do material;

- volume do material;

- origem do fornecedor;

- tipo de frete. 
A análise desses fatores serve como instrumento condutor de informações da atividade de planejamento de materiais, que apresenta três momentos distintos na indústria de computadores:

- O primeiro trata da introdução de novos produtos, em que se destacam as etapas de desenvolvimento de produtos/materiais e também a introdução de novas tecnologias. Nesse momento, todos os esforços são canalizados para que a introdução ocorra no prazo previsto.

- O segundo envolve a sustentação do produto ao longo de sua vida, em que o foco passa a ser atender a pedidos de clientes, mas com valores mínimos de estoque, bem como altos giros de inventário.

- Já o terceiro abrange o fim de vida de um produto, em que o objetivo principal é fazer com que o produto tenha o menor índice de obsolescência possível, ou seja, busca-se um fim de vida com sobra zero de materiais.

A Tabela 3 ilustra esses momentos e suas respectivas prioridades.

\subsection{Modelo predominante de gestão da cadeia de suprimentos (SCM)}

O modelo predominante de SCM na indústria de computadores se adequa as suas características intrínsecas. Contudo, a adoção de determinadas estratégias na SCM incorre em algumas implicações negativas, as quais afetam diretamente o desempenho da cadeia de abastecimento. A seguir, apresenta-se uma análise dessa questão sob a perspectiva de três elementos principais: o produto, a demanda e o abastecimento.

\section{Produtos}

Conforme relatado, a indústria de computadores requer constante redução dos ciclos de vida e aumento da variedade de produtos. Para suportar essa característica, adota-se a estratégia de introduzir o maior número possível de novos produtos, diferenciando-os cada vez mais.

A primeira implicação negativa da adoção dessa estratégia consiste no aumento da complexidade da gestão do ciclo de vida dos produtos, uma vez que novos produtos são lançados a todo o momento e para cada produto há necessidade de perfeita administração de suas quatro fases de vida: a introdução, o crescimento, a maturidade e o declínio. A segunda implicação negativa associa-se ao aumento da gama de materiais, pois na maioria das vezes esses materiais não são intercambiáveis entre os produtos.

Sendo assim, há muitos materiais específicos para cada produto, ou até mesmo para cada variação de produto.

Essas implicações negativas geram uma série de efeitos na cadeia de suprimentos, reduzindo sobremaneira seu desempenho.

Esses efeitos variam desde um considerável aumento na entropia da gestão do ciclo de vida dos produtos até o aumento dos índices de obsolescência de produtos e materiais em geral. Cabe lembrar que o fator obsolescência se potencializa nessa indústria em função de sua constante renovação tecnológica.

Tabela 3 - Prioridades do planejamento de materiais.

\begin{tabular}{llll}
\hline \multicolumn{1}{c}{ Etapa } & \multicolumn{1}{c}{ Introdução } & \multicolumn{1}{c}{ Sustentação } & \multicolumn{1}{c}{ Fim de vida } \\
\hline $\begin{array}{l}\text { Prioridades do } \\
\text { planejamento de } \\
\text { materiais }\end{array}$ & $\begin{array}{l}\text { Atendimento à data de } \\
\text { introdução }\end{array}$ & $\begin{array}{l}\text { Atendimento a ordens } \\
\text { Giro de estoque } \\
\text { Baixo inventário }\end{array}$ & $\begin{array}{l}\text { Índice de } \\
\text { obsolescência zero }\end{array}$ \\
\hline
\end{tabular}


Outro efeito marcante é o aumento dos índices de inventário e a baixa flexibilidade dos materiais, que tendem a cobrir uma enorme gama em termos de abrangência, mas geralmente têm baixo nível de intercambiabilidade de partes.

Esses fatores tornam incompatíveis os objetivos de maior flexibilidade e baixo inventário, pois grandes variedades de materiais requerem altos níveis de estoque para proporcionar flexibilidade satisfatória.

\section{Demanda}

As características da indústria de computadores no tocante à demanda apontam grande variabilidade de mercado, baixa previsibilidade e grande customização de atendimento. Para suportar essas características, adotam-se, muitas vezes, modelos centralizados de gestão da demanda, agrupando, dessa forma, todas as unidades de negócio.

A primeira implicação negativa dessa estratégia consiste na enorme dificuldade em implementar a gestão da demanda. Essa dificuldade é decorrente da adoção de um modelo único de gestão da demanda, que não permite formas diferenciadas de interação da demanda para cada unidade de negócio. As unidades de negócio atuam em segmentos de mercado distintos e, portanto, possuem objetivos diferenciados. Sendo assim, esses objetivos também requerem modelos de gestão diferenciados.

A segunda implicação negativa consiste na total falta de acuracidade das previsões, muitas vezes em função da centralização da gestão da demanda. Essa centralização induz a erros, pois deturpa a visibilidade de condições específicas de mercados regionais e atrapalha o relacionamento entre fabricação e marketing. De maneira geral, essas duas implicações negativas incorrem na falta de acuracidade das previsões da empresa. Por sua vez, essa falta de acuracidade gera uma série de efeitos negativos na cadeia de abastecimento.

$\mathrm{O}$ primeiro efeito negativo associa-se ao falho posicionamento de materiais, em função dos longos lead-times das commodities adquiridas, muitas vezes, de fornecedores da Ásia e com grandes tempos de trânsito e/ou desenvolvimento. Como os materiais são posicionados com base nas previsões de vendas, tem-se que sua não acuracidade incorre em ineficiência de suporte ao atendimento de clientes (flexibilidade) ou em redução dos giros de inventários. Esses dois efeitos são danosos ao retorno do capital investido pela empresa, pois com o não atendimento de clientes perdem-se vendas e diminui-se o lucro líquido. Já na redução dos giros de inventário tem-se aumento do capital investido.

O segundo efeito da falta de acuracidade associa-se ao alto índice de obsolescência, originado na enorme diversidade de produtos e materiais. Essa diversidade prejudica o desempenho da atividade de gestão do ciclo de vida dos produtos.

\section{Abastecimento}

A atual indústria de computadores envolve uma base relativamente grande, e em expansão, de canais de abastecimento. Geralmente, para suportar essa característica adota-se a estratégia da integração eletrônica com todos os fornecedores de primeiro nível (first tier suppliers).

A implicação negativa dessa estratégia devese ao fato de haver interligação eletrônica somente entre fornecedores de primeiro nível. Conforme dito anteriormente, uma gestão efetiva da cadeia de suprimentos requer interligação de todos os níveis produtivos, ou seja, de sua virtual unidade de negócio. O efeito dessa implicação negativa relaciona-se à falta de visibilidade de toda a cadeia de suprimento. A visibilidade somente do primeiro nível incorre em muitos erros de alocação de recursos, pois nem sempre os fornecedores desse primeiro nível repassam a seus subfornecedores a mesma informação de demanda. Por sua vez, essa quebra do canal de informação gera distorções na alocação de recursos de toda a cadeia, acarretando perdas de flexibilidade de atendimento a clientes. 


\subsection{Elementos-chave para o aprimoramento da cadeia de abastecimento}

Objetivando promover melhorias na cadeia de abastecimento da indústria de computadores, esta parte do estudo de caso buscará apresentar os elementos-chave para o aprimoramento: o desenvolvimento de produtos, a gestão da demanda e o fornecimento integrado. Esses elementos são ilustrados na Figura 3.

\subsubsection{Desenvolvimento de produtos}

Conforme descrito anteriormente, a redução dos ciclos de vida e o aumento da gama de produtos são características típicas da indústria de computadores. Assim, qualquer que seja a estratégia relacionada ao desenvolvimento de produtos tem por obrigatoriedade considerar essas características. A proposta aqui apresentada sugere mudanças no desenvolvimento de produtos, as quais se dividem em:

- redução da gama de produtos;

- implementação de estrutura modular;
- aumento da intercambiabilidade de partes.

A redução da gama de produtos, em princípio, aparenta ser uma estratégia equivocada, pois induz ao pensamento de perda de mercado. Contudo, análises revelam que mais de $80 \%$ do faturamento das empresas se concentra em reduzido número de produtos. Portanto, a redução da gama de produtos faz com que o foco das vendas se volte para os produtos que realmente contribuem para o faturamento. No que tange à cadeia de abastecimento, essa redução é extremamente benéfica, pois simplifica e reduz o número de materiais adquiridos e controlados.

Essa simplificação, por sua vez, proporcionaria um aumento da eficiência nos controles de obsolescência e de inventários.

Já a estrutura modular é um conceito que visa minimizar os efeitos prejudiciais da constante redução dos ciclos de vida dos computadores. Nesse conceito, os produtos são desenvolvidos a partir de módulos que, juntos, determinam a configuração final. Basicamente, esses módulos seriam divididos em dois grupos, já apresentados, a plataforma e os configuradores.

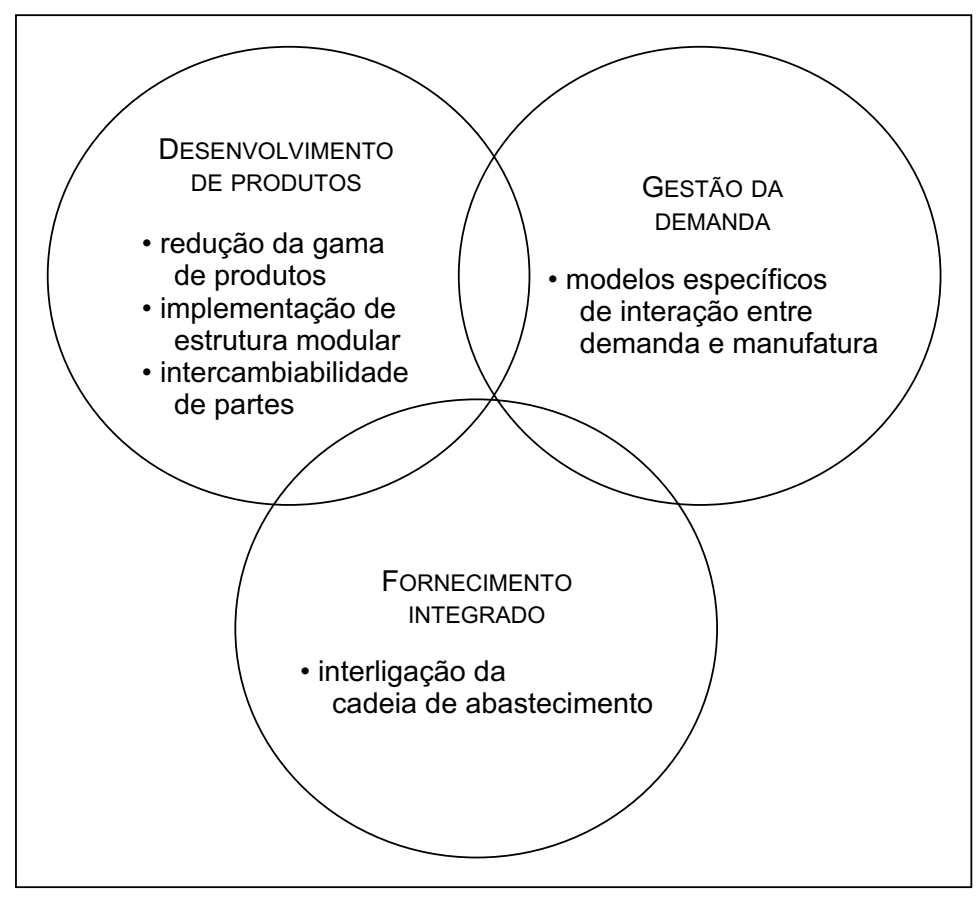

Figura 3 - Elementos de aprimoramento da cadeia de abastecimento. 
A plataforma teria maior estabilidade em seu ciclo de vida e seria totalmente adaptável às constantes trocas de configuradores. Nesse conceito, plataforma e configuradores possuiriam ciclos de vida independentes e predeterminados, cada um associado a sua inovação tecnológica. Dessa maneira, haveria diversas introduções de configuradores associadas à mesma plataforma.

O conceito modular é extremamente favorável ao aprimoramento da cadeia de abastecimento, pois permite melhor controle do ciclo de vida dos produtos, já que a base de controle mudaria de inúmeras CPUs para alguns módulos. Esse aprimoramento proporcionaria melhorias significativas nos índices de obsolescência, advindas de um gerenciamento de fim de vida de produtos mais estruturado, bem como de um melhor controle de introdução de novos produtos.

$\mathrm{O}$ aumento da intercambiabilidade de partes é fundamental ao aprimoramento da gestão de materiais, pois permite atender a diversos produtos a partir de uma base reduzida de suprimentos.

A proposta seria ampliar a intercambiabilidade por meio dos módulos, utilizando um mesmo configurador em diversas plataformas. Assim, os produtos finais apresentariam várias combinações diferentes, geradas a partir de um número limitado de módulos.

Essa intercambiabilidade proporcionaria o aprimoramento do uso dos materiais, que, por sua vez, permitiria significativa redução dos níveis de inventário e, também, melhorias nos níveis de flexibilidade de posicionamento de materiais.

\subsubsection{Gestão da demanda}

A baixa previsibilidade do amplo mercado de computadores faz com que a previsão da demanda se torne uma atividade extremamente complexa e cercada de erros.

Uma proposta para reduzir as margens de erros das previsões seria rever a estratégia predominante de gestão da demanda pela imple- mentação de modelos específicos de interação entre demanda e manufatura para cada unidade de negócio. Essa estratégia se fundamenta no princípio básico de que os mercados das unidades de negócio são diferenciados e apresentam características próprias. Dessa maneira, também são necessários modelos diferenciados de gestão da demanda e, por conseguinte, diferenciadas formas de interação da gestão com a manufatura.

$\mathrm{Na}$ proposta de aprimoramento haveria dois processos distintos de manufatura: a produção para estoque (make to stock - MTS) e a produção sob encomenda (make to order - MTO). A produção para estoque seria mais apropriada para a unidade de negócios de consumidores, visto que apresenta as seguintes características:

- estratégia competitiva com base no custo;

- baixa variedade de produtos;

- grandes volumes;

- definição dos produtos que serão fabricados.

Para essa unidade, um modelo de atendimento baseado em ordens não é muito eficaz, visto que os clientes desse mercado somente compram o que está na prateleira. Também é ineficiente a tentativa de customizar o atendimento nesse mercado, visto que seus clientes priorizam o fator custo e não a diferenciação. Portanto, a estratégia competitiva mais adequada para essa unidade de negócio seria o enfoque no custo.

Outro fator importante é que, com a expansão da Internet, essa unidade de negócio apresenta o maior volume de produção. Por sua vez, esses volumes seriam mais adequados a uma produção em massa.

Em outro extremo, tem-se que a produção sob encomenda se adequaria melhor às unidades de negócio corporativo e de servidores, visto que elas apresentam as seguintes características:

- estratégia competitiva com base na diferenciação;

- grande variedade de produtos; 
- necessidade de capabilidade para qualquer volume;

- postergação da definição final do produto.

A diferenciação no atendimento é um ponto extremamente relevante nos mercados dessas duas divisões, pois cada vez mais seus clientes (mercado corporativo) buscam soluções customizadas para suas necessidades. Portanto, a estratégia competitiva mais adequada a essas unidades de negócio seria o enfoque na diferenciação.

Dessa maneira, a adoção de um modelo MTO associado à proposta de estrutura modular faria com que o ponto de desacoplamento se aproximasse da real entrada de pedidos. Essa proximidade proporcionaria melhor posicionamento de materiais, advindo de um controle mais eficaz das previsões de vendas, que seriam feitas em módulos. Sendo assim, a fabricação (junção dos módulos) teria início somente no ato do recebimento de pedidos. Outro fator benéfico dessa proposta é a flexibilidade de posicionamento de materiais, visto que alguns poucos módulos poderiam atender a uma gama variada de combinações de produtos finais.

\subsubsection{Fornecimento integrado}

Conforme citado anteriormente, tem-se na indústria de computadores um constante aumento dos canais de fornecimento. Por sua vez, esse aumento gera efeitos negativos, que poderiam ser minimizados com a interligação da cadeia de abastecimento. Essa proposta se baseia no crescimento horizontal dos canais de abastecimento (anteriormente descritos) que, por sua vez, dificulta a total visibilidade da alocação de recursos.

$\mathrm{Na}$ indústria de computadores, tem-se a presença de vários fornecedores estratégicos postados em diversas camadas. Dessa maneira, a interligação somente com o primeiro nível não proporciona a visibilidade de toda a cadeia, conforme discutido anteriormente. A proposta aqui apresentada não seria interligar todas as camadas de todos os fornecedores, mas daquelas estrategicamente importantes. Essa interligação permitiria melhor visibilidade de alocação de recursos de toda a cadeia produtiva, fazendo com que a previsão de vendas de computadores fosse transferida para os fornecedores estratégicos, independentemente da camada (first tiers, second tiers, etc.) em que eles se encontrem. Sendo assim, pode-se dizer que essa melhor visibilidade proporcionaria melhor posicionamento de materiais que, por sua vez, permitiria melhor atendimento aos clientes.

\section{Considerações finais}

Atualmente, é notória a crescente importância estratégica da SCM em diversos setores industriais, em especial na indústria de computadores tratada neste artigo. Entretanto, a SCM é um tema extremamente amplo e o foco da pesquisa realizada se limitou à gestão da cadeia de abastecimento (inbound), ou seja, às relações dos fornecedores (upstream) da empresa estudada.

A análise realizada em uma grande empresa do setor sugere a necessidade de constante aprimoramento da SCM, visando a resultados positivos não somente no âmbito das empresas produtoras de computadores, mas também para seus fornecedores e para a cadeia de abastecimento em geral. Esses benefícios estão ligados a melhorias em alguns processos, como previsões de vendas, racionalização de produtos e materiais e interligação das camadas de fornecedores.

A análise apontou que o aprimoramento da cadeia de abastecimento necessariamente está atrelado à revisão da SCM como um todo, sugerindo que a possível racionalização dessa cadeia estaria ligada à revisão de sua estratégia de SCM.

Dessa maneira, o resultado de uma possível melhoria de desempenho, conforme sugerido neste artigo, necessariamente estaria inserido na redefinição e/ou alteração das estratégias de SCM das empresas do setor. 
Finalmente, cabe observar que, embora baseada em um estudo de caso em uma grande e representativa empresa multinacional produtora de computadores, a pesquisa indica que muitas das questões aqui tratadas são representativas do setor industrial e não apenas de uma grande empresa. Nesse caso, as limitações intrínsecas às pesquisas exploratórias e o cuidado com a não identificação da empresa estudada não permitem avançar mais no relato da análise.

\title{
Referências Bibliográficas
}

CHRISTOPHER, M. Logística e gerenciamento da cadeia de suprimentos. São Paulo: Pioneira, 1997.

CHRISTOPHER, M.; BRAITHWAITE, A. Managing strategic lead times. London: Logistics Information Management Publications, 1989.

COLLINS, R. S.; BECHLER, K.; PIRES, S. Outsourcing in the automotive industry: from JIT to modular consortia. European Management Journal, v. 15, n. 5, oct. 1997.

COOPER, M. C.; GARDNER, J. T. Building good business relationships - More than just partnering or strategic alliances. International Journal of Physical Distribution \& Logistics Management, v. 23, n. 6, 1993.

DANE, F. C. Research methods. Belmont, California: Brooks/Cole, 1990.

PIRES, S. Gestão da cadeia de suprimentos e o modelo do consórcio modular. Revista de Administração/USP, São Paulo, v. 33, n. 3, 1998.
PIRES, S.; BREMER, C.; SANTA EULÁLIA, L.; GOULART, C. Supply chain and virtual enterprises: comparisons, migration and a case study. International Journal of Logistics: Research and Applications, v. 4, n. 3, 2001.

POIRIER, C. C.; REITER, S. E. Otimizando sua rede de negócios. São Paulo: Futura, 1997.

PORTER, M. Competitive strategy. New York: Free Press, 1980.

SLACK, N. et al. Administração da produção. São Paulo: Atlas, 1996.

SVENSSON, G. The theoretical foundation of supply chain management - a functionalist theory of marketing. International Journal of Physical Distribution \& Logistics Management, v. 32, n. 9, 2002.

VOLLMANN, T. E.; CORDON, C. Supply chain management. Business Briefing - Manufacturing 2000, Forum. n. 18, Lausanne: IMD, Summer 1996.

\section{AN ANALYSIS OF SUPPLY CHAIN MANAGEMENT IN THE COMPUTER INDUSTRY}

\begin{abstract}
During the last years, competition has increased significantly in the industrial world and has created a set of new challenges and opportunities in the way of organizing and managing the production. In this context, supply chain management has emerged as a new and promising frontier for reaching competitive advantages within the marketplace. On the other hand, the computer industry shows a series of characteristics that make difficult to achieve effectiveness in the supply chain management, due mainly to the speed of the technological innovations in the sector. This article has the basic purpose of showing a general analysis of the supply chain management within the computer industry and with focus on its inbound chain. The research was supported by a research conducted in a large and representative worldwide computer manufacturer operating in Brazil.
\end{abstract}

Key words: supply chain management, computer industry, inbound chain management. 